\title{
Does plant performance under stress explain divergent life history strategies? The effects of flooding and nutrient stress on two wetland sedges
}

\author{
Nate Hough-Snee ${ }^{\mathrm{a}, *}$, Lloyd L. Nackley ${ }^{\mathrm{a}, \mathrm{b}}$, Soo-Hyung Kim ${ }^{\mathrm{a}}$, Kern Ewing ${ }^{\mathrm{a}}$ \\ a University of Washington, School of Environmental and Forest Sciences and Center for Urban Horticulture, PO Box 352100, Seattle, WA 98195-2100, USA \\ ${ }^{\mathrm{b}}$ University of Cape Town, Department of Biological Sciences, Private Bag X3, Rondebosch, Cape Town 7701, South Africa
}

\section{A R T I C L E I N F O}

\section{Article history:}

Received 15 August 2013

Received in revised form 9 March 2014

Accepted 14 March 2014

Available online $\mathrm{xxx}$

\section{Keywords:}

Plant strategies

Functional traits

Carex

Biomass allocation

Niche partitioning

Environmental stress

\begin{abstract}
A B S T R A C T
Novel hydrology and nutrient loads are common environmental filters in disturbed wetlands. These filters impact plant growth and influence the composition and productivity of wetland plant communities by selecting for flooding-tolerant species that can efficiently acquire and use nutrients. We performed a factorial greenhouse trial to elucidate how nutrients and flooding affect the growth and morphology of Carex obnupta and Carex stipata, two wetland sedges with divergent life history strategies. Individual seedlings of each species were exposed to a combination of flooding (deep or shallow) and fertilization (low or high) treatments. These treatment combinations create a stress gradient from high fertilization and shallow flooding (lowest stress) to low fertilization and deep flooding (highest stress). Plant biomass accumulation and allocation were measured after 77-days. Total biomass, leaf area, and shoot biomass were greatest in high fertilizer treatments, regardless of flooding treatment. There was an initial plant size effect in C. obnupta: small plants accumulated less biomass than large plants under high flooding. $C$. stipata had higher biomass and specific leaf areas than C. obnupta in all treatments. C. obnupta had higher net assimilation rates per unit biomass and leaf area than $C$. stipata. These stress responses illustrate that each species has a distinct life history strategy. C. obnupta is a stress tolerator that can persist across a range of flooding conditions. C. stipata is a ruderal species that outgrows flooding stress by allocating carbon to leaf growth. These species' niches likely diverge based on how each species grows and allocates biomass under environmental stress
\end{abstract}

(c) 2014 Elsevier B.V. All rights reserved.

\section{Introduction}

Plant communities arise as products of biotic and abiotic environmental filters that shape plant species' growth and reproduction that drive interspecific competition (Keddy, 1992; Woodward and Diament, 1991). Environmental filters are any non-random process that shapes species assembly in a given environment (Díaz et al., 2007). Plant community composition shifts across environmental gradients based on species' functional capacities to acclimate to local environmental conditions (Cornwell and Ackerly, 2009; Wright and Westoby, 1999). As soil resources and/or environmental stress change across space or time, species that cannot acclimate to local conditions become less competitive and eventually fail to

\footnotetext{
* Corresponding author at: Utah State University, Ecology Center and Department of Watershed Sciences, 5210 Old Main Hill, Logan, UT 84322-5210, USA. Tel.: +1 4355355085 .

E-mail address: nate@natehough-snee.org (N. Hough-Snee).
}

successfully reproduce and maintain their place in a community (Díaz et al., 1998). This theory of community assembly dictates that a species' life history strategy must correspond to the local physical, chemical and biotic environments for it to persist (Keddy, 1992). The traits that comprise the life history strategies that govern community assembly may be most easily elucidated across strong environmental gradients, such as those found in wetland ecosystems.

Wetland vascular plants have evolved functional strategies to tolerate environmental stress and acquire the resources required to persist, grow, and reproduce under suboptimal conditions. Accordingly, wetland plant communities often assemble across hydrologic gradients (Keddy, 1992; Shaffer et al., 1999; van Eck et al., 2004), as the depth, duration and timing of flooding stress select for wetland plant species with morphological and physiological adaptations that match a given environment (Keddy, 2000; Kozlowski, 1984; Magee and Kentula, 2005). To not be "filtered" out of a community, wetland plant species must be able to not only tolerate flooding stress, but also effectively acquire environmental 
resources such as nutrients and light. While general plant strategies have been classified based on functional traits that allow individual plant species to thrive and compete in different environmental settings (Grime, 2001; Kahmen and Poschlod, 2004) many species' life history strategies and their corresponding functional traits have not been assessed. Within this study we assess the abilities of two common wetland species, Carex obnupta and Carex stipata, to acclimate to persistent stress by quantifying how their functional traits-physiological and morphological characteristics that govern growth and reproduction-respond to the common wetland stressors and subsidies, flooding and nutrients.

To understand how each species will respond to wetland stresssubsidy dynamics, it is important to understand how each stressor (flooding and low nutrition) and subsidy (high nutrition) influences plant performance. Flooding reduces the oxygen available to submerged plant tissues and inhibits aerobic root respiration and active metabolic processes including nutrient and water uptake (Laanbroek, 1990). Plant responses to flooding are determined by belowground tissue oxygen acquisition and the expansion of leaf area relative to overall growth (Evans and Poorter, 2001). For many plants, including Carex species, flooding triggers the formation of aerenchyma-porous tissues that allow oxygen to diffuse within plant tissues (Chen et al., 2002; Visser et al., 2000). Within Carices, aerenchyma occurs predominantly by lysigenous processes where root tissues die and are replaced by new aerenchymous tissues (Visser et al., 2000). Proportional increases in root allocation to form aerenchyma may occur at the expense of plant growth because as relative photosynthetic tissue biomass decreases, so do photosynthetic carbon gain (Mielke et al., 2003).

Flooding not only changes plant allocation patterns, but also reduces leaf-level photosynthesis in many species (Kozlowski, 1984; Mielke et al., 2003). However, whole-plant photosynthesis may remain high due to high pre-stress specific leaf areas, the unit leaf area per unit leaf mass (SLA;(Shipley et al., 2005). High SLA allows fast-growing plants to maintain growth during flooded conditions, even when leaf-level photosynthesis is reduced (Bailey-Serres and Voesenek, 2008; Mommer et al., 2006). When an additional environmental stress, like low soil fertility, is paired with flooding, stressors may exacerbate flooding stress (Pezeshki, 2001; Pezeshki et al., 1999), selecting against species unable to build and maintain tissues under multiple stressors.

In contrast to flooding stress, nutrient enrichment is a common anthropogenic impact on wetlands (Verhoeven et al., 1993) and may increase plant nutrient uptake, photosynthesis and growth (DeLaune et al., 1998; Mcjannet et al., 1995). Wetland plant performance is enhanced by nutrient enrichment when plants are able to acclimate to the anoxic environment and essential nutrients do not occur exclusively as toxic, reduced compounds (Johnson and Leopold, 1994; Laanbroek, 1990; Merino et al., 2008; Rey Benayas and Scheiner, 1993). Fertile conditions are associated with high total productivity in wetlands at the expense of plant diversity as fast-growing, resource-efficient species outcompete stress-tolerant species (Bedford et al., 1999; Grime, 1977; Moore et al., 1989). This trade off between productivity and diversity in enriched environments may be explained by enhanced physiological performance (Laanbroek, 1990; McJannet et al., 1995) or biomass allocation strategies that allow plants to escape stress and continue to grow (Voesenek et al., 2004, 1992). In this way soil nutrition filters species that cannot use extra soil resources, favoring ruderal species that can quickly turn these resources into biomass.

Plants growing in flooded and nutrient-limited environments may allocate more biomass to roots, increasing root surface area to acquire nutrients (Morris and Ganf, 2001; Rubio et al., $1995)$ and oxygen. Anaerobic conditions created by flooding limit roots' ability to acquire nitrogen $(\mathrm{N})$, specifically nitrate $\left(\mathrm{NO}_{3}\right)$, decreasing tissue nitrogen content and photosynthesis (Willby et al., 2001). Aerenchyma allows oxygen to diffuse into the soil, providing an oxidized buffer where nitrate remains soluble for plant uptake, enabling continued aboveground growth and photosynthesis. Building aerenchymous roots that acquire oxygen allows for continued plant growth facilitates a "low oxygen escape syndrome" life strategy (Bailey-Serres and Voesenek, 2008; Colmer and Voesenek, 2009). Low oxygen escape syndrome can occur rapidly in enriched, flooded conditions where sufficient photosynthesis maintains rigid stem architecture, expedites aerenchyma formation and allows leaf growth to continue (Blom and Voesenek, 1996). This rapid leaf expansion strategy in response to prolonged flooding has been shown to enhance the survival and growth of wetland plants in numerous settings (Pierik et al., 2008; Voesenek et al., 2004). However, differences in low oxygen escape strategy have not been evaluated among species known to occupy different environmental niches (Merino et al., 2008; Morris and Ganf, 2001).

C. stipata and C. obnupta occupy distinct niches in wetland environments and we anticipate that their functional responses to stress will explain these differences. While both species occur in wetlands, the types of wetlands they're capable of occupying (potential niche) may differ based on their ability to acclimate to stress and subsidy. We ask the question, does each species' performance under environmental stress explain its potential niche? To define how each species responds to flooding stress and nutrient susbsidy, we addressed intraspecific and interspecific hypotheses on plant biomass accumulation and allocation. Intraspecific hypotheses compare individual species' performance across the range of treatments:

Environmental stress from high flooding and low nutrients will shape plant allocation and biomass accumulation. We anticipate that flooded plants or nutrient-stressed plants will accumulate less total biomass, have lower leaf areas and specific leaf area, and allocate a greater proportion of total biomass to roots than in unflooded and well fertilized plants.

Specifically, we expect that plants experiencing shallow flooding and high fertilization will accumulate more total biomass than plants experiencing deep flooding and high fertilization or deep flooding and low fertilization and accumulate high leaf area, and show high specific leaf area, leaf mass ratio and leaf area ratio. We also anticipate that high flooding may be overcome by high fertilization that allows plants to outgrow environmental stress.

The interspecific hypotheses address differences in the growth and allocation of the two species based on their life-history strategies:

Deciduous $C$. stipata will exhibit low oxygen escape syndromelike properties when flooded, rapidly growing leaves and producing more total biomass than $C$. obnupta, with higher specific leaf area and leaf area ratios. The evergreen $C$. obnupta will be more flood-tolerant than C. stipata, growing slowly and thriving under high nutrient conditions required to produce long-lived, evergreen leaves with high leaf mass ratios and low specific leaf areas. Specifically, we anticipate that $C$. stipata will have higher leaf area ratios and specific leaf areas and a lower leaf mass ratio than $C$. obnupta. We anticipate that $C$. stipata will photosynthesize less per unit leaf area and per unit total biomass, but have greater total leaf areas than C. obnupta.

\section{Materials and methods}

\subsection{Plant species and experimental rationale}

To evaluate the stress responses of two wetland sedges under a combination of flooding and fertilization treatments, we established a greenhouse experiment in June 2009 at the University of 
Washington Center for Urban Horticulture (Seattle, WA, USA). C. obnupta (slough sedge) and C. stipata (awlfruit sedge) were selected as experimental species for their regional abundance in wetlands of the U.S. Pacific Northwest as well as the global distribution of the genus Carex (Cyperaceae). C. obnupta is an evergreen, rhizomatous species that occurs from British Columbia, Canada, to northern California, USA in wetlands with variable hydroperiods including coastal marshes, hydric forests, riparian zones and tidal channels (Wilson, 2008). It occurs commonly in hydric, organic soils that experience their deepest flooding in winter (Minore, 1969), and spreads rapidly by rhizome and seed, forming dense monocultures in many habitats. C. stipata is a deciduous, tussock-forming species that inhabits wetland edges and seasonally wet habitats across North America, Europe and eastern Asia (Wilson, 2008). C. stipata is common in meadows and wet prairies but rarely occurs in deep, open water (Magee and Kentula, 2005), and does not grow well under prolonged flooding (Ewing, 1996). C. stipata seeds have been shown to exhibit reduced dormancy (Hough-Snee and Cooper, 2011; Kettenring and Galatowitsch, 2007) and are dispersed by buoyant perigynia.

\subsection{Plant materials and allocation to experimental treatments}

In May of 2009, one hundred 6-month old bare-root seedlings of each species were acquired from a nursery (Fourth Corner Native Plants, Bellingham, WA, USA). Initial wet biomass was measured for each seedling before individual seedlings were planted into 3.81 plastic pots containing $\sim 3.71$ of seed-sterilized sand. We selected sand substrate to allow better nutrient control (Fig. S1) and ensure heterogeneous capillary action in the soil column. Seedlings were randomized and placed onto greenhouse benches where they were watered and monitored for mortality for three weeks. Both species experienced transplant stress and mortality, shedding leaves immediately following transplant. Of the seedlings that survived the hardening off period, 60 individuals of each species were randomly selected for inclusion in the experiment. The 60 plants of each species were rank-ordered 1-60 by initial wet weight and plants were stratified into four groups based on weight $(N=60$, $n=15, k=4$ ). For example, plants with weight ranks of one, two, three, and four were allocated to four different groups, a, b, c and d. Ranked plants were then continuously allocated to the four different groups to prevent the random clumping of plants into size clusters (all plants large or all plants small) that might confound treatment effects. Following stratification, each group of plants (a, b, c, and d) was randomly assigned to a fully-crossed experimental treatment combination of flooding and fertilization.

\subsection{Experimental design and treatments}

A fully crossed, factorial experiment was undertaken in which individuals of both species were exposed to combinations of two flooding levels and two fertilization levels. The shallow flooding treatment consisted of each plant being placed into an individual five-liter plastic bucket and filled to a depth of $5 \mathrm{~cm}(\approx 600 \mathrm{ml})$ inundating the bottom third of the rooting zone while maintaining aerated conditions elsewhere in the root zone. The deep flooding treatment partially submerged plants in individual buckets that were filled to $4 \mathrm{~cm}$ above the substrate level $(\approx 5000 \mathrm{ml})$. The low fertilization treatment consisted of a modified, one-eighth strength Hoagland's solution while the high fertilization treatment consisted of a modified, half-strength Hoagland's solution (Table S1; (Kinmonth-Schultz and Kim, 2011). These fertilization levels provided nutrient concentrations that were potentially limiting (low) or in excess of the minimum amounts required for plant growth (high). Combinations of the nutrient and flooding treatments are referred to with two letter codes. For example, high nutrients, deep flooding = HD; low nutrients, shallow flooding = LS, etc (Table S2).

Consistent growing conditions were maintained during the experiment by discarding and replacing treatment solutions on a weekly basis. To compensate for evapotranspirational water loss between treatment replacements, solution levels were refilled daily with deionized water to the assigned flooding depth. Plants were evenly spaced on greenhouse benches to prevent canopy effects and re-randomized across benches weekly. Greenhouse temperatures ranged from 17 to $29^{\circ} \mathrm{C}$ and the light period consisted of artificial light levels set at $14 \mathrm{~h}$ per day at $\approx 1200 \mu \mathrm{mol} \mathrm{m}^{2} \mathrm{~s}^{-1}$ around midday throughout the duration of the experiment. Ambient natural light within the greenhouse was as high as $1700 \mu \mathrm{mol} \mathrm{m}^{2} \mathrm{~s}^{-1}$.

\subsection{Photosynthesis, plant biomass and allocation}

Seven seedlings of each species from each treatment combination (28 plants per species) were harvested on day 31 of the trial (results not presented here). The remaining 64 plants, 32 of each species, were harvested on day 77 and are referred to as the second harvest $\left(\mathrm{h}_{2}\right.$; Table S2). Prior to destructive harvest, four individuals of each species and treatment combination were measured for net carbon assimilation across a range of ambient $\mathrm{CO}_{2}$ levels (Hough-Snee, 2010). We graphically present photosynthesis per unit leaf area and per unit leaf mass from the $400 \mu \mathrm{mol} \mathrm{mol}^{-1} \mathrm{CO}_{2}$ level to aid interpretation of plant allocation and morphological data. At each harvest leaf area and whole plant wet biomass were measured and each plant was separated into two sections: aboveground (stems and shoots), and belowground (roots and rhizomes). The biomass from each plant was dried to a constant weight at $80^{\circ} \mathrm{C}$ for $72 \mathrm{~h}$. Dried biomass was measured for aboveground and belowground portions. Additionally, leaf area ratio (LAR), leaf mass ratio (LMR) and specific leaf area (SLA) were calculated for each plant to assess how the treatments were affecting the proportional allocation to the photosynthetic surfaces. LMR is defined as the proportion of leaf biomass to total plant biomass while SLA is the ratio of leaf area to leaf biomass. LAR is the product of SLA and LMR (Causton and Venus, 1981). With the exception of leaf area and wet weight, all biomass results presented herein use dry biomass values. Herein, we discuss analyses and results only from the second harvest $\left(h_{2}\right)$.

\subsection{Statistical analyses}

At the time of stratification and treatment allocation, one-way ANOVA was used to test the null hypothesis that initial plant size did not differ between the four treatment combinations for each species. For total biomass, leaf area, root:shoot ratio, aboveground biomass, belowground biomass, LAR, LMR and SLA, a two-way factorial analysis of covariance (ANCOVA) was used to test for differences in treatment group means using plant initial wet weight as a covariate. Tests were performed independently for each species. Tukey pairwise comparisons were made within each species including the initial wet weight as a covariate. Combined fertilization and flooding effects on photosynthesis were compared only between species at each treatment combination using $T$-tests with Bonferroni-corrected $p$-values. For interspecific hypotheses, we tested the difference in means between each species at each treatment combination using pairwise $T$-tests with Bonferroni-adjusted $p$-values for each species at a given treatment combination. Interspecific hypotheses were tested independently from intraspecific hypotheses because our re-randomization scheme within the greenhouse prevented block or gradient effects within the greenhouse from compromising independence between experimental units. Test results were considered significant at 
an alpha level of $p<0.05$. Prior to analyses, data were assessed for normality and homogeneous variance using Shapiro-Wilk and Bartlett's tests and log transformed as necessary. All data are presented untransformed. Statistical analyses were performed in $\mathrm{R}$ version 2.9.1 (R Development Core Team, 2011).

\section{Results}

Initial wet weights ranged from $5.5 \mathrm{~g}$ to $80.6 \mathrm{~g}$ with a mean of $29.48 \mathrm{~g}$ for C. stipata, and from $3.8 \mathrm{~g}$ to $61.8 \mathrm{~g}$ with a mean of $22.32 \mathrm{~g}$ for $C$. obnupta. Mean plant wet weights did not significantly differ between treatment groups for either species prior to experimental treatments began ( $p=0.24$ for $C$. stipata; $p=0.94$ for C. obnupta).

Harvest results for $C$. obnupta showed the highest total biomass, leaf areas, aboveground biomass, and belowground biomass in the least stressful highly fertilized, shallow flooding, (HS) treatment (Fig. 1; Table S3). For C. obnupta the lowest total biomass, leaf areas, aboveground biomass, and belowground biomass were all measured in the low fertilization, shallow flooding, (LS) treatment group (Fig. 1). Differences in C. obnupta total biomass, leaf area, above- and belowground biomass, could be attributed to fertilization and initial wet weight effects (Table 1). Flooding was also a significant factor in determining C. obnupta belowground biomass growth. Total biomass, leaf areas, and aboveground biomass of $C$. obnupta did not differ between deep and shallow flooding treatments within a given fertilizer treatment (Fig. 1). C. obnupta belowground biomass was highest in the HS treatment (Fig. 1). Flooding and fertilization, significantly affected C. obnupta root:shoot ratio (R:S). Plants grown with low nutrients or shallow flooding had proportionally greater R:S than their counterparts in the high nutrients or deep flooding treatments. Differences in $C$. obnupta leaf morphology (LAR, SLA, and LMR) were significantly influenced by fertilization. LMR was also significantly affected by the flooding treatment. Pairwise comparisons revealed that there were not significant LAR differences within nutrient treatments, SLA only differed between HS and LD treatments. Leaf mass ratio only differed between HD and LS (Fig. 2).

Differences in C. stipata total biomass and leaf areas could be primarily attributed to flooding (Table 1, Fig. 1). Unlike $C$. obnupta, initial C. stipata seedling wet weights did not affect final total biomass or leaf areas. While the most biomass accumulated in C. obnupta in the HS treatment, for C. stipata the greatest total biomass, leaf areas, aboveground biomass, and belowground biomass were in the HD group (Fig. 1). Similar to C. obnupta, the least total aboveground and belowground biomass and lowest leaf areas were measured for C. stipata in the LS treatment combination (Fig. 1). Although the general responses to fertilization were similar between species, total biomass was greater in deciduous C. stipata (Fig. 1) than evergreen C. obnupta. The R:S ratio for $C$. stipata followed the same pattern as C. obnupta, with the greatest R:S occurring in the LS group, and the lowest R:S ratio in the HD treatment. Root:shoot ratios were attributable to both flooding and fertilization. Differences in C. stipata LAR were primarily attributable to fertilization, with no significant differences within flooding treatments within either fertilizer group (Fig. 2). Flooding-fertilization interaction terms were only significant for $C$. stipata (Figs. 1-2). Specifically, wet weight, leaf area, aboveground biomass, total biomass and root-to shoot-ratio were influenced by flooding-fertilization interactions. For $C$. stipata SLA, there were no significant differences between any treatment combinations. $C$. stipata LMR was affected by both flooding and fertilization, with significant differences between flooding treatments within the high nutrient treatment, and between high and low nutrients (Fig. 2). Net carbon assimilation did not differ between treatments within $C$. obnupta. Within C. stipata the HS treatment had significantly higher photosynthesis per unit mass than the other treatment combinations (Fig. 3).

Between the two species, there were numerous differences in allocation, morphology and photosynthesis at each treatment combination (Figs. 1-3). Total biomass, leaf area, and R:S ratio were higher in C. stipata than C. obnupta at the same treatment levels (Fig. 1). Within high fertilization treatments at both flooding levels, C. stipata produced more above and belowground biomass than C. obnupta (Fig. 1). Between C. stipata and C. obnupta LAR, SLA and LMR differed at each treatment combination (Fig. 2). Leaf area ratio and SLA were higher in C. stipata, showing that it accumulated the most leaf area per unit total biomass and per unit leaf biomass. Leaf mass ratio was highest in C. obnupta showing that it preferentially allocated biomass to thick leaves.

\section{Discussion}

\subsection{Plant biomass and allocation}

Previous research has demonstrated that Carices (C. limosa, $C$. sempervirens, $C$. rostrata and $C$. davalliana) proportionally allocate biomass to roots when submerged or partially flooded (Visser et al., 2000). Our results suggest that this flooding response can be mitigated under eutrophic conditions in fast-growing Carex species. For instance, in high fertility treatments individuals of both species proportionally allocated less biomass to roots than unfertilized individuals of the same flooding treatment. Both species' allocation responses to flooding and nutrients show that Carex responses to flooding may be driven by available soil resources. Nutrients generally exerted a stronger effect on total biomass and leaf area than flooding in C. obnupta and C. stipata (Table 1; Figs. 1-3), indicating that nutritional subsidy is more important than flooding stress in shaping plant morphology and allocation.

We observed rapid fertilization-driven leaf area expansion in both species regardless of flooding level. Both species effectively utilize soil resources to overcome flooding stress, but $C$. stipata builds thin and short-lived leaves very quickly (Figs. 2-3). The allocation costs of building new leaves is higher for evergreen species than deciduous species (Aerts, 1995; Wright et al., 2004). Accordingly, initial plant size had a more significant effect on C. obnupta total, and above- and belowground biomass, than on the same metrics in deciduous $C$. stipata. Photosynthesis was also lower per unit leaf mass for C. obnupta than for C. stipata (Fig. 3). C. stipata showed lower photosynthesis per unit leaf area, indicating that it has a less efficient canopy, and perhaps lower construction costs per unit leaf mass than $C$. obnupta under all treatments. This observation corresponds to the high leaf mass ratios and thick leaves of $C$. obnupta. Increased size at planting has been shown to correspond to greater growth, final plant height, and survival in Carex nebrascensis, C. rostrata, and C. lanuginosa in riparian meadows (Steed and DeWald, 2003), and may be a product of total canopy area. Size effects may influence how rapidly individual plants can overcome resource limitations and also how plants compete with one another across environmental gradients. Larger individual Carices, especially of evergreen species with thick leaves (low SLA), may compete more effectively as plant tissue resources help individuals to rapidly increase whole plant photosynthesis and growth under stress (Poorter et al., 2009).

The reduced LAR and LMR observed in the LD and LS treatments are consistent with other studies that have shown SLA to limit growth in infertile environments (Poorter and Remkes, 1990). Similar to our findings, it has been shown that coupling nutrient stress with other stressors can significantly reduce LAR in emergent wetland plants (Morris and Ganf, 2001). For example, as the duration and depth of flooding increased in Genipa americana seedlings, LMR 


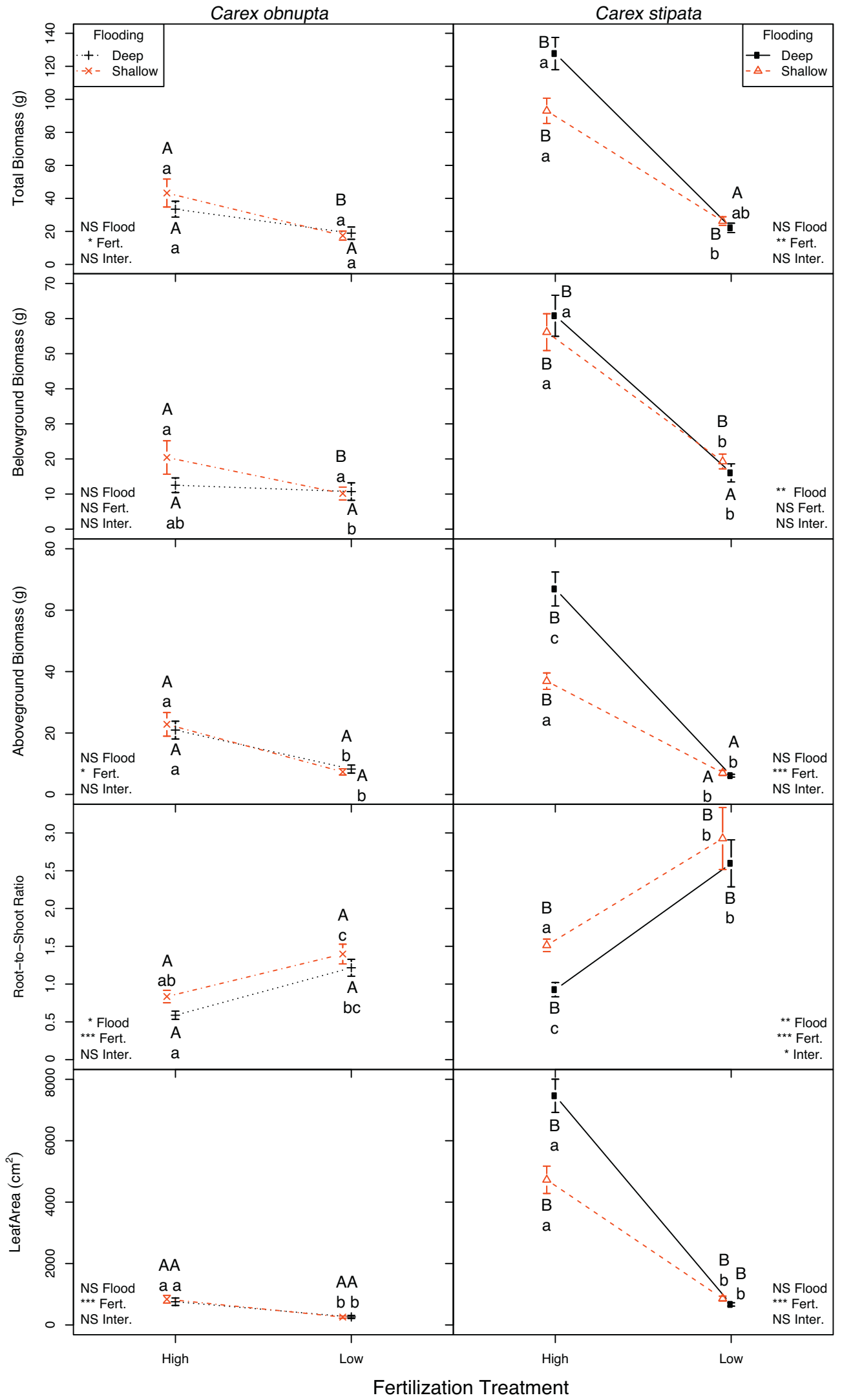

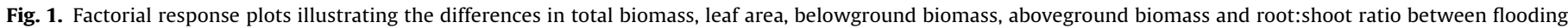

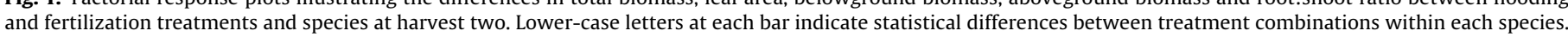
Upper-case letters indicate statistically significant interspecific differences between $C$. obnupta and $C$. stipata within a given treatment combination. 
Table 1

Final biomass allocation weights, leaf area, and root-to-shoot ratio ANCOVA results for $\mathrm{h}_{2}$ significant $(p<0.05)$ probability values are reported below.

\begin{tabular}{|c|c|c|c|c|c|}
\hline Growth parameter & Species & Initial wet weight & Flooding & Fertilization & $\begin{array}{l}\text { Flooding-fertilization } \\
\text { interaction }\end{array}$ \\
\hline \multirow[t]{2}{*}{ Wet weight } & C. obnupta & $p<0.01$ & - & $p<0.01$ & - \\
\hline & C. stipata & - & - & $p<0.01$ & $p=0.023$ \\
\hline \multirow[t]{2}{*}{ Leaf area } & C. obnupta & $p<0.01$ & - & $p<0.01$ & - \\
\hline & C. stipata & - & - & $p<0.01$ & $p<0.01$ \\
\hline \multirow[t]{2}{*}{ Aboveground biomass } & C. obnupta & $p<0.01$ & - & $p<0.01$ & - \\
\hline & C. stipata & - & - & $p<0.01$ & $p<0.01$ \\
\hline \multirow[t]{2}{*}{ Total biomass } & C. obnupta & $p<0.01$ & - & $p<0.01$ & - \\
\hline & C. stipata & - & $p=0.01$ & $p<0.01$ & $p<0.01$ \\
\hline \multirow[t]{2}{*}{ Belowground biomass } & C. obnupta & $p<0.01$ & $p=0.05$ & $p<0.01$ & - \\
\hline & C. stipata & - & - & $p<0.01$ & - \\
\hline \multirow[t]{2}{*}{ Root-to-shoot ratio } & C. obnupta & - & $p=0.01$ & $p<0.01$ & - \\
\hline & C. stipata & - & $p<0.01$ & $p<0.01$ & $p=0.05$ \\
\hline \multirow[t]{2}{*}{ Leaf area ratio } & C. obnupta & - & - & $p<0.01$ & - \\
\hline & C. stipata & $p=0.06$ & - & $p<0.01$ & - \\
\hline \multirow[t]{2}{*}{ Specific leaf area } & C. obnupta & - & - & $p=0.044$ & - \\
\hline & C. stipata & - & $p=0.02$ & - & - \\
\hline \multirow[t]{2}{*}{ Leaf mass ratio } & C. obnupta & $p=0.04$ & $p=0.02$ & $p<0.01$ & - \\
\hline & C. stipata & - & $p=0.01$ & $p<0.01$ & - \\
\hline
\end{tabular}

and LAR both decreased (Mielke et al., 2003). Flooding depth influences SLA in numerous species (Jung et al., 2010), while leaf area, specifically LAR, of which SLA is a component process, may drive plant growth (Evans and Poorter, 2001; Shipley, 2006).

\subsection{Carex and stress: Linking stress responses to plant life history strategies}

C. obnupta and C. stipata had distinct responses to flooding and fertilization in their growth, morphology, and biomass allocation. The relationships between plant persistence across fertility and flooding gradients commonly show tradeoffs between growth and resource acquisition in productive environments and the effective conservation of resources under stressful conditions (Poorter and Remkes, 1990; Rubio et al., 1995; Willby et al., 2001). As each species experiences amenable conditions for growth - highly fertile, flooded conditions for C. stipata and fertile, saturated conditions for C. obnupta - it may increase total photosynthetic biomass, whole plant photosynthesis and relative growth rates. High growth rates correspond to high LARs and low R:S indicative of high canopy carbon gains rather than belowground tissue allocation for acclimating to flooding and nutrient stress. It is possible that both species initially expanded their leaf areas in response to flooding stress, but the costs of building new evergreen leaves amid limited oxygen within flooded treatments forced C. obnupta to grow less rapidly by the end of the trial. Another deciduous wetland species, Rumex palustris, has been shown to preferentially elongate petioles and expand leaf area in response to flooding (Bailey-Serres and Voesenek, 2008; Pierik et al., 2008; Voesenek et al., 2004), allowing the plant to acclimate to flooding over long timeframes. These observations help to explain not only the life strategy and realized habitats of both sedges, but also provide insights to each species' range of potential niches across theses gradients.

The dynamic wetland environments that sedges inhabit may expose plants to additional stressors such as drying, sediment accumulation or herbivory that further shape their functional traits and select for specific life history strategies. For example, as the distance to water table decreased, transplants of Carex utriculata were shown to survive at greater rates in riparian meadows than those plants that never experienced root-zone flooding (Sarr and Dudley, 2008). Drying following flooding also reduces gas exchange in $C$. stipata (Ewing, 1996). Post anoxic injury is common in many plant species following flooding, so perhaps to better define the environmental limitations to $C$. obnupta and $C$. stipata performance, these species should be subject to flooding and drying regimes similar to the hydrographs of many wetlands where they commonly occur (Ewing, 1996). If wetland hydrology has shifted to extreme wet and dry periods, like many urban and disturbed wetlands, the dual stressors of flooding and drying will likely affect many plant life stages, including reproduction. For example, hydrology might strongly affect the germination of $C$. stipata seed, its most common reproductive strategy. Elucidating the limitations to seedling emergence in response to seasonal flooding and water table draw-downs would be of great use in predicting how altered hydroperiods might change wetland plant communities by altering suitable habitat availability over time. Further investigation could examine how each species responds to flooding and fertilization from germination onward and over longer timeframes. The temporal scale at which rhizomatous species such as C. obnupta expand is often longer than the duration of this trial, allowing for limited inference on how flooding and fertilization might influence the reproduction dynamics and long-term population demographics of the species.

While short-duration flooding may not be a limiting factor for the successful growth of larger, established individuals of $C$. obnupta and $C$. stipata, flooding stress is exacerbated by nutrient limitations that reduce leaf level and whole plant photosynthesis, leaf area expansion, and plant growth in both species. C. stipata, while widely distributed, may only be dominant in environments where it can rapidly expand its leaf area and increase plant total biomass to outgrow stress early. C. stipata may be more adversely affected by flooding during the seedling stage immediately following seed germination. If plants adapted to outgrow flooding are too small to extend a 'straw' above floodwater surfaces and continue gas exchange, then they may not persist in that environment. The capability to outgrow flooding is only particularly useful in situations where flooding is shallow and prolonged (Voesenek et al., 2004), such as the HD and LD treatments within this study. $C$. stipata performs poorly in infertile environments, showing a stresstolerant- ruderal life history strategy (Grime, 1977) that may not perform well in low-nutrient wetlands such as fens and bogs.

C. obnupta shows a competitive-stress tolerator strategy (sensu Grime, 1977) as it persists in flooded environments with high nutrient levels that allow for the creation and maintenance of efficient, long-lived evergreen leaves. Paired flooding stress and nutrient limitation may affect small C. obnupta individuals more adversely than large individuals. Unlike C. stipata, C. obnupta lacks the ability to rapidly increase specific leaf area and expand total photosynthetic area to overcome flooding stress. This may also explain why these species are not often found in the same types of wetlands. Our SLA results imply that $C$. stipata may also compete 


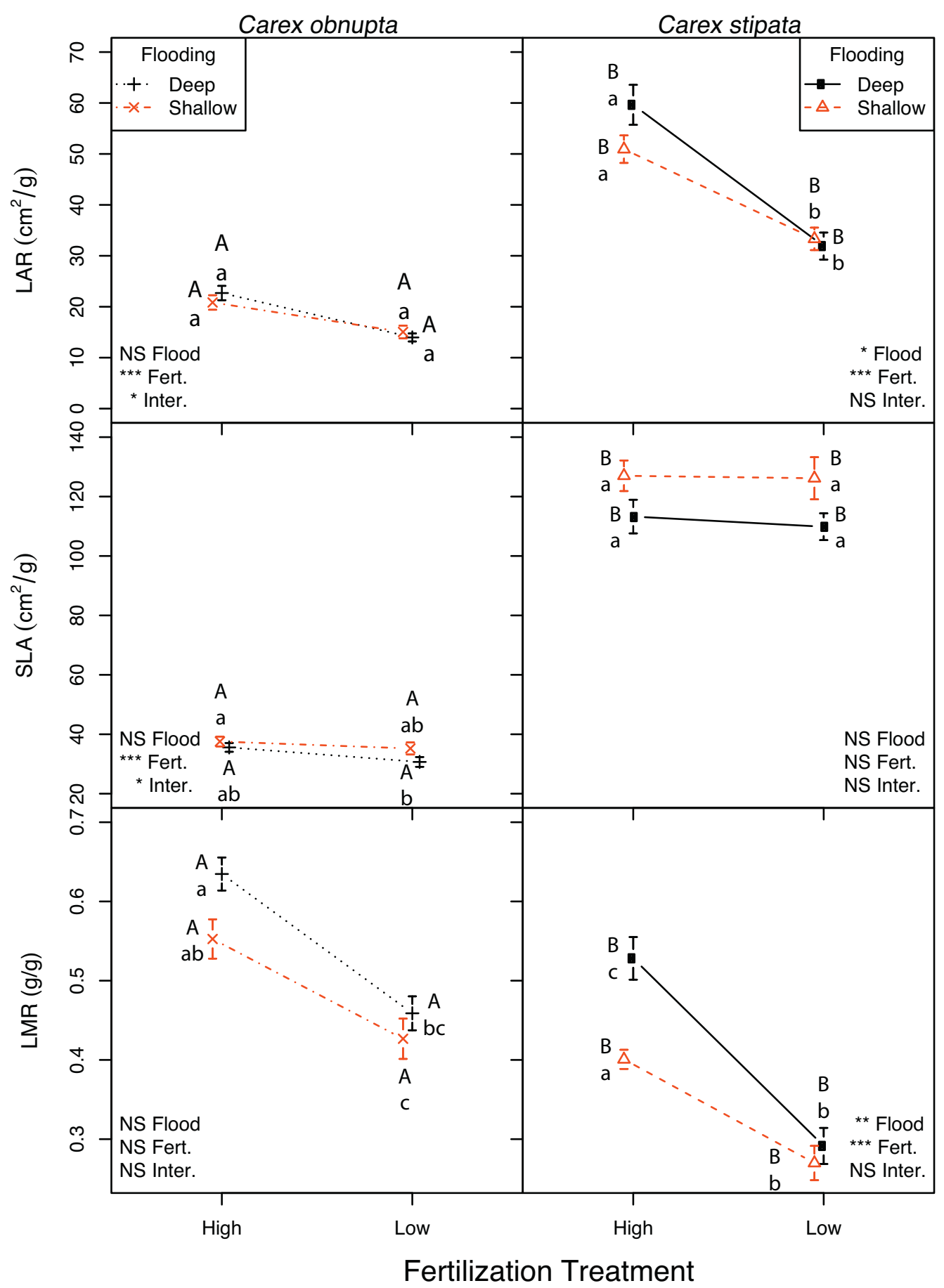

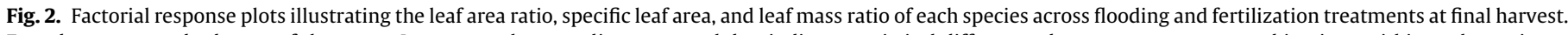

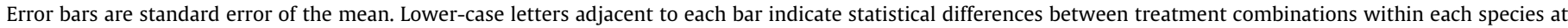
each harvest. Upper-case letters indicate statistically significant interspecific differences between C. obnupta and C. stipata within a given treatment combination.

well with invasive plants that employ similar ruderal strategies. C. obnupta, which can expand through large rhizome networks, may expand more slowly, but may be able to persist under some invasion pressure-in part because of the flooded environments that it inhabits and partly because competing species may not be able to recruit into dense rhizomatous monocultures.

This study investigated how individuals of two Carex species responded to prolonged flooding and nutrient subsidy or stress. We identified that $C$. obnupta has a stress-tolerating strategy that relies on existing canopy biomass to ensure consistent growth and
C. stipata uses a rapidly growing low-oxygen escape strategy to outgrow stress. Each species' functional responses to environmental stress help to explain their realized niches. Additionally these stress responses illustrate both species potential niches in novel wetland environments. Our findings have implications for how each species competes within communities and persist through new environmental filters like urban hydrology or agricultural nutrient subsidies. By understanding how these species respond to stress, inference can be made on how sedge-dominated wetland communities might change under different anthropogenic stressors. 


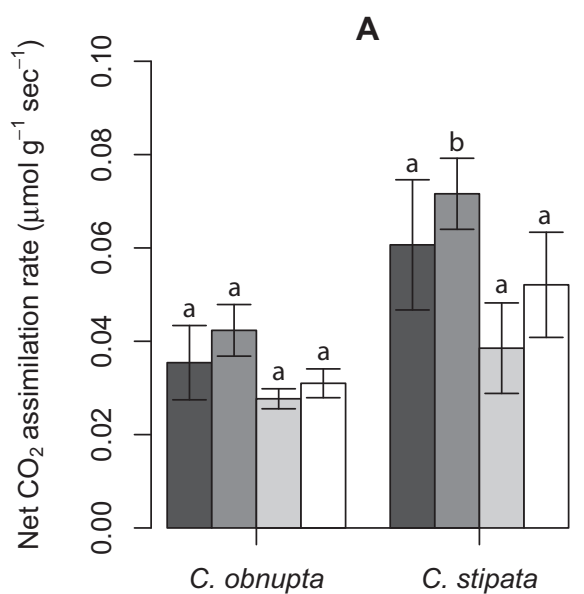

Species

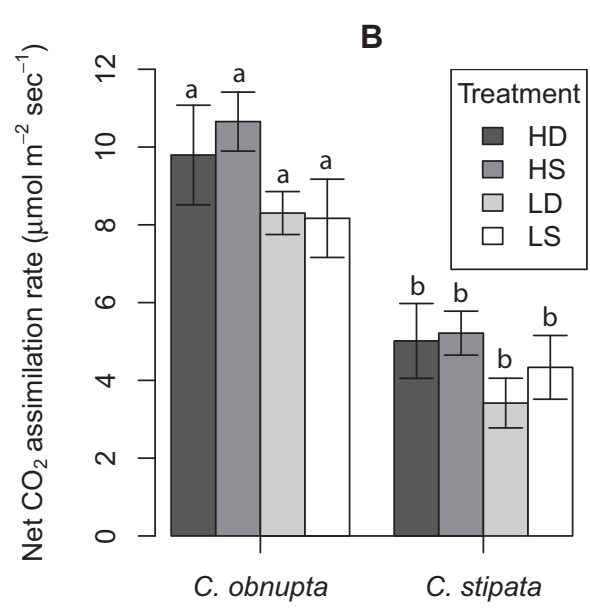

Species

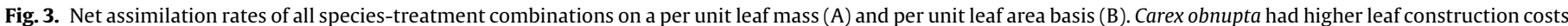

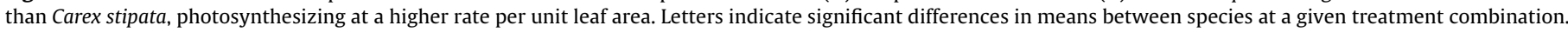
Error bars are standard error of the mean.

\section{Acknowledgments}

We thank Joel Bombardier, Derrick Cooper, Lexine Long, and Kurt Zogorski for greenhouse assistance. The University of Washington Botanic Gardens generously provided greenhouse workspace. We extend our gratitude to Rodney Pond, Lexine Long, Gregory Ettl, Elisabeth Gross, and three anonymous reviewers for providing comments that greatly improved drafts of this manuscript.

\section{Appendix A. Supplementary data}

Supplementary data associated with this article can be found, in the online version, at http://dx.doi.org/10.1016/j. aquabot.2014.03.001.

\section{References}

Aerts, R., 1995. The advantages of being evergreen. Trends Ecol. Evol. 10, 402-407. Bailey-Serres, J., Voesenek, L.A.C.J., 2008. Flooding stress: acclimations and genetic diversity. Annu. Rev. Plant Biol. 59, 313-339.

Bedford, B.L., Walbridge, M.R., Aldous, A., 1999. Patterns in nutrient availability and plant diversity of temperate North American wetlands. Ecology 80, 2151-2169.

Blom, C.W.P.M., Voesenek, L.A.C.J., 1996. Flooding: the survival strategies of plants. Trends Ecol. Evol. 11, 290-295.

Causton, D.R., Venus, J.C., 1981. The Biometry of Plant Growth. Edward Arnold, London.

Chen, H., Qualls, R.G., Miller, G.C., 2002. Adaptive responses of Lepidium latifolium to soil flooding: biomass allocation, adventitious rooting, aerenchyma formation and ethylene production. Environ. Exp. Bot. 48, 119-128.

Colmer, T.D., Voesenek, L.A.C.J., 2009. Flooding tolerance: suites of plant traits in variable environments. Funct. Plant Biol. 36, 665

Cornwell, W.K., Ackerly, D.D., 2009. Community assembly and shifts in plant trait distributions across an environmental gradient in coastal California. Ecol. Monogr. 79, 109-126.

DeLaune, R.D., Pezeshki, S.R., Lindau, C.W., 1998. Influence of soil redox potential on nitrogen uptake and growth of wetland Oak seedlings. J. Plant Nutr. 21, 757-768.

Díaz, S., Cabido, M., Casanoves, F., 1998. Plant functional traits and environmental filters at a regional scale. J. Veg. Sci. 9, 113-122.

Díaz, S., Lavorel, S., Chapin, F.S., Tecco, P.A., Gurvich, D.E., Grigulis, K., 2007. Functional diversity at the crossroads between ecosystem functioning and environmental filters. In: Canadell, J.G., Pataki, D.E., Pitelka, L.F. (Eds.), Terrestrial Ecosystems in a Changing World. Springer Berlin Heidelberg, Berlin, Heidelberg, pp. 81-91.

Evans, J.R., Poorter, H., 2001. Photosynthetic acclimation of plants to growth irradiance: the relative importance of specific leaf area and nitrogen partitioning in maximizing carbon gain. Plant Cell Environ. 24, 755-767.

Ewing, K., 1996. Tolerance of four wetland plant species to flooding and sediment deposition. Environ. Exp. Bot. 36, 131-146.

Grime, J.P., 1977. Evidence for the existence of three primary strategies in plants and its relevance to ecological and evolutionary theory. Am. Nat., 1169-1194.
Grime, J.P., 2001. Plant Strategies, Vegetation Processes, and Ecosystem Properties Wiley, New York, NY.

Hough-Snee, N., Cooper, D.D., 2011. Perigynium removal improves seed germination in awl-fruit sedge (Carex stipata). Native Plants J. 12, 41-44.

Hough-Snee, N.W., 2010. The Effects of Flooding Depth, Fertilization and Initia Seedling Size on the Growth and Biomass Allocation of Two Wetland Sedges, Carex obnupta and Carex stipata. University of Washington, Seattle, WA.

Johnson, A.M., Leopold, D.J., 1994. Vascular plant species richness and rarity across a minerotrophic gradient in wetlands of St. Lawrence County, New York, USA Biodivers. Conserv. 3, 606-627.

Jung, V., Violle, C., Mondy, C., Hoffmann, L., Muller, S., 2010. Intraspecific variability and trait-based community assembly. J. Ecol. 98, 1134-1140.

Kahmen, S., Poschlod, P., 2004. Plant functional trait responses to grassland succession over 25 years. J. Veg. Sci. 15, 21-32.

Keddy, P.A., 1992. Assembly and response rules: two goals for predictive community ecology. J. Veg. Sci. 3, 157-164.

Keddy, P.A., 2000. Wetland ecology: principles and conservation. In: Cambridge Studies in Ecology. Cambridge University Press, Cambridge, UK; New York, NY.

Kettenring, K.M., Galatowitsch, S.M., 2007. Tools for Carex revegetation in freshwater wetlands: understanding dormancy loss and germination temperature requirements. Plant Ecol. 193, 157-169.

Kinmonth-Schultz, H., Kim, S.-H., 2011. Carbon gain, allocation and storage in rhizomes in response to elevated atmospheric carbon dioxide and nutrient supply in a perennial C3 grass, Phalaris arundinacea. Funct. Plant Biol. 38, 797.

Kozlowski, T.T., 1984. Plant responses to flooding of soil. BioScience 34, 162-167.

Laanbroek, H.J., 1990. Bacterial cycling of minerals that affect plant growth in waterlogged soils: a review. Aquat. Bot. 38, 109-125.

Magee, T.K., Kentula, M.E., 2005. Response of wetland plant species to hydrologic conditions. Wetlands Ecol. Manage. 13, 163-181.

McJannet, C.L., Keddy, P.A., Pick, F.R., 1995. Nitrogen and phosphorus tissue concentrations in 41 wetland plants: a comparison across habitats and functiona groups. Funct. Ecol. 9, 231-238.

Merino, J.H., Huval, D., Nyman, A.J., 2008. Implication of nutrient and salinity interaction on the productivity of Spartina patens. Wetlands Ecol. Manage. 18, $111-117$

Mielke, M.S., de Almeida, A.-A.F., Gomes, F.P., Aguilar, M.A.G., Mangabeira, P.A.O. 2003. Leaf gas exchange, chlorophyll fluorescence and growth responses of Genipa americana seedlings to soil flooding. Environ. Exp. Bot. 50, 221-231.

Minore, D., 1969. Yellow skunk-cabbage (Lysichitum Americanum)-an indicator of water-tabledepth. Ecology 50, 737.

Mommer, L., Lenssen, J.P.M., Huber, H., Visser, E.J.W., De Kroon, H., 2006. Ecophysiological determinants of plant performance under flooding: a comparative study of seven plant families. J. Ecol. 94, 1117-1129.

Moore, D.R.J., Keddy, P.A., Gaudet, C.L., Wisheu, I.C., 1989. Conservation of wetlands: do infertile wetlands deserve a higher priority? Biol. Conserv. 47, 203-217.

Morris, K., Ganf, G.G., 2001. The response of an emergent sedge Bolboschoenus medianus to salinity and nutrients. Aquat. Bot. 70, 311-328.

Pezeshki, S.R., 2001. Wetland plant responses to soil flooding. Environ. Exp. Bot. 46 299-312.

Pezeshki, S.R., DeLaune, R.D., Anderson, P.H., 1999. Effect of flooding on elemental uptake and biomass allocation in seedlings of three bottomland tree species. J. Plant Nutr. 22, 1481-1494.

Pierik, R., van Aken, J.M., Voesenek, L.A.C.J., 2008. Is elongation-induced leaf emergence beneficial for submerged Rumex species? Ann. Bot. 103, 353-357.

Poorter, H., Remkes, C., 1990. Leaf area ratio and net assimilation rate of 24 wild species differing in relative growth rate. Oecologia 83, 553-559. 
G Model

AQBOT-2659; No. of Pages 9

N. Hough-Snee et al. / Aquatic Botany xxx (2014) xxx-xxx

9

Poorter, H., Niinemets, Ü., Poorter, L., Wright, I.J., Villar, R., 2009. Causes and conequinces of variation in leaf mass per area (LMA): a meta-analysis. New Phytol. $182,565-588$.

R Development Core Team, 2011. R: A Language and Environment for Statistical Computing. R Development Core Team, Vienna, Austria.

key Benayas, J.M., Scheiner, S.M., 1993. Diversity patterns of wet meadows along geochemical gradients in central Spain. J. Veg. Sci. 4, 103-108.

Rubin, G., Casasola, G., Lavado, R.S., 1995. Adaptations and biomass production of two grasses in response to waterlogging and soil nutrient enrichment. Oecologia $102,102-105$.

Sari, D.A., Dudley, T.L., 2008. Survival and restoration potential of beaked sedge (Care utriculata) in grazed riparian meadows of the southern Sierra Nevada (California). Ecol. Rector. 26, 186-188.

Shaffer, P.W., Kentula, M.E., Grin, S.E., 1999. Characterization of wetland hydrology using hydrogeomorphic classification. Wetlands 19, 490-504.

Shipley, B., 2006. Net assimilation rate, specific leaf area and leaf mass ratio: which is most closely correlated with relative growth rate? A meta-analysis. Funct. Ecol. 20, 565-574

Shipley, B., Vile, D., Garner, E., Wright, I.J., Poorter, H., 2005. Functional linkages between leaf traits and net photosynthetic rate: reconciling empirical and mechanistic models. Funct. Ecol. 19, 602-615.

Steed, J.E., DeWald, L.E., 2003. Transplanting sedges (Care spp.) in Southwestern riparian meadows. Restor. Ecol. 11, 247-256.

Van Eck, W.H.J.M., van de Steeg, H.M., Blow, C.W.P.M., de Kroon, H., 2004. Is tolerance to summer flooding correlated with distribution patterns in river floodplains? A comparative study of 20 terrestrial grassland species. Oiks 107, 393-405.

Verhoeven, J.T.A., Kemmers, R.H., Koerselman, W., 1993. Nutrient enrichment of freshwater wetlands. In: Voc, C.C., Opdam, P. (Eds.), Landscape Ecology of a
Stressed Environment. Springer Netherlands, Dordrecht, The Netherlands, pp. 33-59.

Visser, E.J.W., BöGemann, G.M., Van De Steeg, H.M., Pierik, R., Blow, C.W.P.M., 2000. Flooding tolerance of Care species in relation to field distribution and aerenchyma formation. New Phytol. 148, 93-103.

Voesenek, L.A.C.J., Rijnders, J.H.G.M., Peeters, A.J.M., van de Steeg, H.M., de Kroon, H., 2004. Plant hormones regulate fast shoot elongation under water: from genes to communities. Ecology 85, 16-27.

Voesenek, L.A.C.J., Stan, A.J.M., Herren, F.J.M., Blow, C.W.P.M., 1992. An amalgamaction between hormone physiology and plant ecology: a review on flooding resistance and ethylene. J. Plant Growth Regul. 11, 171-188.

Willy, N.J., Pulford, I.D., Flowers, T.H., 2001. Tissue nutrient signatures predict herbaceous-wetland community responses to nutrient availability. New Phytol. $152,463-481$.

Wilson, B.L., 2008. Field Guide to the Sedges of the Pacific Northwest. Oregon State University Press, Corvallis, OR.

Woodward, F.I., Diament, A.D., 1991. Functional approaches to predicting the ecological effects of global change. Funct. Ecol. 5, 202-212.

Wright, I.J., Reich, P.B., Westoby, M., Ackerly, D.D., Baruch, Z., Bongers, F., CavenderBares, J., Chain, T., Cornelissen, J.H.C., Diemer, M., Flexas, J., Garner, E., Groom, P.K., Gulas, J., Hikosaka, K., Lamont, B.B., Lee, T., Lee, W., Luik, C., Midgley, J.J., Novas, M.-L., Niinemets, U., Oleksyn, J., Osada, N., Poorter, H., Poot, P., Prior, L., Pyankov, V.I., Roumet, C., Thomas, S.C., Tjoelker, M.G., Veneklaas, E.J., Velar, R., 2004. The worldwide leaf economics spectrum. Nature 428, 821-827.

Wright, I.J., Westoby, M., 1999. Differences in seedling growth behavior among species: trait correlations across species, and trait shifts along nutrient compared to rainfall gradients. J. Ecol. 87, 85-97.

Please cite this article in press as: Hough-Snee, N., et al., Does plant performance under stress explain divergent life history strategies?

The effects of flooding and nutrient stress on two wetland sedges. Aqua. Bot. (2014), http://dx.doi.org/10.1016/j.aquabot.2014.03.001 